\title{
Diabetes Mellitus and Metformin: Fatal Vitamin B12 Deficiency Associated with Anemia and Sepsis in a Young Adult
}

\author{
Anuvarsha Katroth', Anusha Narayanam², Sheetal Chauhan', Ajit Singh" \\ 'Sree Chaitanya Institute of Pharmaceutical Sciences, Karimnagar, Telangana, India-500501. \\ ${ }^{2}$ Malla Reddy College of Pharmacy, Maisammaguda, Hyderabad, India-500014. \\ ${ }^{3}$ Department of Pharmacology, Melaka Manipal Medical College, Manipal University, Manipal-576104 India. \\ ${ }^{4}$ Department of Cardiology, Kasturba Medical College and Hospital, Manipal University, Manipal-576104 India.
}

\begin{tabular}{l}
\hline ARTICLE INFO \\
\hline Article history: \\
Received on: 08/12/2017 \\
Accepted on: $26 / 01 / 2018$ \\
Available online: $30 / 03 / 2018$ \\
\hline Key words: \\
Megaloblastic anemia, Met- \\
formin-induced neuropathy, \\
Diabetic foot, Diabetic \\
ulcers.
\end{tabular}

\section{INTRODUCTION}

Metformin is a most prescribed oral hypoglycaemic agent, used in the management of diabetes mellitus (T2DM). Metformin is compatible with a maximum number of drugs and conditions with fewer contraindications and lesser drug interaction profile. The drug is preferred with lifestyle modifications for the better therapeutic outcome. Few studies have reported the metformin-associated Vitamin B12 (VitB12) deficiency on extensive and long-term use (Kang et al., 2014; Liu et al., 2014). VitB12 deficiency leads to anemia and peripheral neuropathy in T2DM patients (Reinstatler et al., 2012). Here we present a case of metformin-associated vitamin B12 deficiency that led to fatal anemia and sepsis in a young adult with T2DM.

\footnotetext{
${ }^{*}$ Corresponding Author

Ajit Singh, Research Associate, Department of Cardiology, Kasturba Medical College and Hospital, Manipal University, Manipal-576104. E-mail: ajitjsingh.mcops@gmail.com
}

\section{CASE REPORT}

A 42 years old male presented to the AMCU (Acute Multi Care Unit) department of a tertiary care hospital at Karimnagar, a South Indian district, with the multiple small ulcers on the bilateral lower limbs till toe for four weeks with numbness, tingling sensation and leg pain. The patient also complained the severe fatigue, dyspnoea on exertion and difficulty in walking for 2 months. On physical examination he was pallor. He had a history of T2DM for 9 years and continuing a single drug metformin 500 $\mathrm{mg}$ twice daily for 5 years. In the family, his father also had T2DM and continued oral hypoglycemic agents. All possible causes of lower limb injuries were ruled out. Bilateral lower limb arterial and venous doppler showed normal flow without obstruction. $\mathrm{He}$ has provisionally diagnosed to have diabetes-related foot ulcers. At admission, his lab investigations showed borderline high sugar levels. At day 1 his fasting blood sugar (FBS), random blood sugar (RBS) and glycosylated haemoglobin ( $\mathrm{HbAlC}$ ) were near normal; $124 \mathrm{mg} / \mathrm{dL}, 148 \mathrm{mg} / \mathrm{dL}$ and $6.2 \mathrm{mmol} / \mathrm{L}$ respectively. Liver, thyroid and kidney function test were normal. Haematological studies showed the severe anemia. Hemoglobin level, haematocrit 
and total red blood cells (TRBC) were $6.2 \mathrm{~g} / \mathrm{dL}, 28 \%$ and $2.7 \times 10^{3}$ cells/microL respectively.

For foot ulcers, preliminary dressings were done with antiseptics. Serum procalcitonin (ProCT) and blood culture were sent for suspected wound infections/sepsis. ProCT was negative for bacterial infection with the value of $0.02 \mathrm{ng} / \mathrm{mL}$ and two out of three blood samples showed staphylococcus and beta-haemolytic streptococci species growth after 24 hours.

Surgery and gastroenterology opinions were sought to rule out the possible causes of anemia i.e. gastric ulcers. Ultrasound (USG) abdomen and oesophago-gastro duodenoscopy (OGD scopy) showed no gastrointestinal ulcer. As per the patient's note, there is no active bleeding from foot ulcers.

The iron profile was tested which shows degraded serum iron, ferritin and total iron binding capacity (TIBC) levels; $45 \mathrm{mcg} /$ $\mathrm{dL}, 26 \mathrm{ng} / \mathrm{mL}$ and $470 \mathrm{mcg} / \mathrm{dL}$ respectively. Mean corpuscular volume (MCV) and Mean corpuscular hemoglobin $(\mathrm{MCH})$ levels were increased; $176 \mathrm{fL} / \mathrm{cell}$ and $56 \mathrm{pg} /$ cell respectively where mean corpuscular hemoglobin concentration (MCHC) was slight high (44 g/dL). A blood smear analysis showed senile neutrophils, poikilocytosis, the presence of macrocytes and anisocytosis. The VitB12 level was $55 \mathrm{pg} / \mathrm{mL}$, which is much lesser than the standard and possible cause of anemia. Metformin-induced VitB12 deficiency was suspected because of long-term use of metformin. Coomb's test was negative. These all findings suggested the final diagnosis of 'Megaloblastic anemia' due to VitB12 deficiency.

As per the provisional diagnosis and lab investigations, metformin was discontinued and glimepiride $1 \mathrm{mg}$ twice daily was started. Cefotaxime $1 \mathrm{~g}$ twice daily was started for bacterial infection. Acetaminophen and pantoprazole along with IV fluids were given as supportive measures.

Table 1: Showing laboratory investigations during hospitalization.

\begin{tabular}{lccccc}
\hline Parameters & $\begin{array}{c}\text { At admission } \\
\text { (Day 1) }\end{array}$ & Day 2 & Day 3 & Day 4 & Day 5 \\
\hline Temperature (degree F) & 98.4 & 100.2 & 98.8 & 99.0 & 98.7 \\
Hemoglobin (gm/dl) & 6.2 & 6.8 & 5.8 & 5.2 & 5.0 \\
Hematocrit (\%) & 28 & 26 & 26 & 22 & 25 \\
TRBC (×103 cells/ & 2.7 & - & 2.2 & - & 2.0 \\
microL) & & & $1.6 \times$ & - & $1.4 \times$ \\
Platelet counts (cells/ & $1.7 \times 10^{3}$ & - & $10^{3}$ & & $10^{3}$ \\
mL) & 9700 & - & 17000 & 13000 & 14000 \\
TWBC (cells/cumm) & 67 & - & 68 & - & 56 \\
Neutrophils (\%) & 30 & - & 27 & - & 32 \\
Lymphocytes (\%) & 3 & - & 5 & - & 2 \\
Esinophils (\%) & 148 & 86 & 137 & 128 & 102 \\
RBS (mg/dl) & 124 & 98 & 96 & 109 & 97 \\
FBS (mg/dl) & 6.2 & - & - & - & - \\
HbAlc (\%) & 18 & - & 20 & - & 26 \\
Blood urea (mgs\%) & & - & 1.1 & - & 1.3 \\
Serum Creatinine (mg/ & 0.9 & & - & 25.54 & - \\
dL) & & & & & \\
Serum Procalcitonin & 0.02 & - & & & \\
(ProCT) ng/mL & & & & & \\
\hline
\end{tabular}

Treatment was given based on the symptoms, severity of the condition and laboratory investigations. For first three days 2-pint PRBC/day were transfused and 1 pint on the $4^{\text {th }}$ day but hemoglobin levels were not improved. Repeat ProCT was highly positive on the $4^{\text {th }}$ day of admission for suspected sepsis. The antibiotic-resistant test was done and intravenous meropenem 500 $\mathrm{mg}$ twice daily has started as per the resistance reports. At fifth day afternoon, patient's dyspnoea has worsened suddenly and while shifting to Intensive care unit, he succumbed.

\section{DISCUSSION}

Metformin is the drug widely used to treat T2DM and found to be safe as first-line therapy with lifestyle modifications (Kumthekar and Gidwani, 2012). It is also useful in polycystic ovary syndrome (PCOS) and insulin resistance conditions with the positive effect on vascular protection, weight loss and carbohydrate metabolism. Vitamin B12 deficiency is the detrimental effect of metformin processed by malabsorption of vitamin B12 (Liu et al., 2014).

Almost 30\% patients develop vitamin B12 deficiency on long-term metformin therapy. Longer duration of metformin therapy and dose are the factors associated with metformininduced vitamin B12 deficiency. Increasing the dose of metformin to $1 \mathrm{~g}$ /day increases the twofold higher risk of VitB12 deficiency where dose increment to $2 \mathrm{~g}$ /day increases the risk fourfold. Longterm use of metformin (3-5 years) can decrease the VitB12 levels by $30-50 \%$ (Kang et al., 2014; Singh and Baheti, 2016; Aroda et al., 2016). It leads to metformin-induced neuropathy (Ting et al., 2006).

The exact mechanism of VitB12 deficiency is controversial. Adopted mechanism shows the slow gut mobility, stimulation of bacterial overgrowth and the increased consumption of VitB12 by bacteria. It can alter the level of intrinsic factor which could affect vitamin B12 absorption adversely. The metformin may also inhibit Calcium-dependent absorption of the vitamin B12. Metformin also inhibits the intrinsic factor complex at the terminal ileum (Kumthekar and Gidwani, 2012; Jager et al., 2010). Metformin also contributes to glucose-6-phosphate dehydrogenase (G6PD) mediated hemolysis (Kirkiz et al., 2013; Meir et al., 2003).

The National Health and Nutrition Examination Survey 1999-2006, noticed that the 6\% patients had developed VitB12 in T2DM patients taking metformin. This survey and Institute of Medicine recommended the administration of VitB12 at 2.4 micrograms/day for continuation; general multivitamins are not sufficient to prevent the crisis (Reinstatler et al., 2012). There are no specific guidelines about the screening of metformin-induced VitB12 deficiency, but few studies and health organizations recommend the VitB12 routine screening before and after metformin use. Serum methylmalonic acid (MMA) and homocysteine levels screening also considerable in T2DM patients with borderline VitB12 (Singh and Baheti, 2016; Kibirige and Mwebaze, 2013).

Sepsis can change the mechanical and functional properties of red blood cells (RBCs). It alters the oxygencarrying capacity of RBCs and rheology of microcirculation. Other blood components including platelets can also lose their functional capabilities by an alteration in erythron. It prevents the 
improvement in $\mathrm{Hb}$ and PRBCs levels inspite transfusion (Goyette et al., 2004). Transfusion-related acute lung injury (TRALI), haemolytic transfusion reactions and transfusion-associated circulatory overload (TACO) are the transfusion complications occurs acutely within $6 \mathrm{~h}$ to $72 \mathrm{~h}$. In this case, delayed reactions or transfusion-related worsening of infection is suspected (Sadaka, 2013).

\section{CONCLUSION}

Long-term use of metformin can cause the severe VitB12 and anemia. Sepsis or infections can even worsen the condition by transfusion failure mechanism. This case is not criticising the efficacy and better safety profile of metformin, but the clinicians and patients should be aware of the screening, duration of therapy and complications related to metformin use which can be lifethreatening or fatal. Proper care of wounds, diabetic foot and an early visit to clinician can prevent that kind of situations.

\section{INFORMED CONSENT}

Written Informed consent was taken from the patient before examination and publication.

\section{CONFLICT OF INTEREST}

There are no conflicts of interest.

\section{REFERENCES}

Aroda VR, Edelstein SL, Goldberg RB, Knowler WC, Marcovina SM, Orchard TJ, Bray GA, Schade DS, Temprosa MG, White $\mathrm{NH}$, Crandall JP. Long-term metformin use and vitamin B12 deficiency in the Diabetes Prevention Program Outcomes Study. The Journal of Clinical Endocrinology \& Metabolism. 2016 Feb 22;101(4):1754-61.

De Jager J, Kooy A, Lehert P, Wulffele M, van der Kolk J, Bets $\mathrm{D}$ et al. Long term treatment with metformin in patients with type 2 diabetes and risk of vitamin B-12 deficiency: randomised placebo controlled trial. BMJ. 2010;340(may19 4):c2181-c2181.

Goyette R, Key N, Ely E. Hematologic Changes in Sepsis and Their Therapeutic Implications. Seminars in Respiratory and Critical Care Medicine. 2004;25(06):645-659.
Jeetendra S, Tushar B. Metformin Use and Vitamin B 12 Deficiency in Patients with Type-2 Diabetes Mellitus. MVP Journal of Medical Sciences. 2016 Feb 29;3(1):67-70.

Kang D, Yun J, Ko S, Lim T, Ahn Y, Park Y et al. Higher Prevalence of Metformin-Induced Vitamin B12 Deficiency in Sulfonylurea Combination Compared with Insulin Combination in Patients with Type 2 Diabetes: A Cross-Sectional Study. PLoS ONE. 2014;9(10):e109878.

Kibirige D, Mwebaze R. Vitamin B12 deficiency among patients with diabetes mellitus: is routine screening and supplementation justified? Journal of Diabetes \& Metabolic Disorders. 2013;12(1):17.

Kirkiz S, Yarali N, Arman Bilir O, Tunc B. Metformin-Induced Hemolytic Anemia. Medical Principles and Practice. 2013;23(2):183-185.

Kumthekar A, Gidwani H. Metformin Associated Vitamin B12 Deficiency. Journal of the Association of Physicians of India. 2012;60:5859.

Liu Q, Li S, Quan H, Li J. Vitamin B12 Status in Metformin Treated Patients: Systematic Review. PLoS ONE. 2014;9(6):e100379.

Meir A, Kleinman Y, Rund D, Da'as N. Metformin-Induced Hemolytic Anemia in a Patient With Glucose-6-Phosphate Dehydrogenase Deficiency. Diabetes Care. 2003;26(3):956-957.

Reinstatler L, Qi YP, Williamson RS, Garn JV, Oakley GP. Association of biochemical B12 deficiency with metformin therapy and vitamin B12 supplements. Diabetes care. 2012 Feb 1;35(2):327-33.

Sadaka F. Red Blood Cell Transfusion in Sepsis: A Review. Journal of Blood Disorders \& Transfusion. 2013;s4.

Ting R. Risk Factors of Vitamin B12 Deficiency in Patients Receiving Metformin. Archives of Internal Medicine. 2006;166(18):1975.

Singh J, Baheti T. Metformin Use and Vitamin B 12 Deficiency in Patients with Type-2 Diabetes Mellitus. MVP Journal of Medical Science. 2016 Feb 29;3(1):67-70.

How to cite this article:

Katroth A, Narayanam A, Chauhan S, Singh A. Diabetes Mellitus and Metformin: Fatal Vitamin B12 Deficiency Associated with Anemia and Sepsis in a Young Adult. J App Pharm Sci, 2018; 8(03): 165-167. 